\title{
Clinical Study \\ Efficacy of Autologous Bone Marrow Concentrate for Knee Osteoarthritis with and without Adipose Graft
}

\author{
Christopher Centeno, ${ }^{1}$ John Pitts, ${ }^{1}$ Hasan Al-Sayegh, ${ }^{1}$ and Michael Freeman ${ }^{2}$ \\ ${ }^{1}$ Regenerative Sciences, The Centeno-Schultz Clinic, 403 Summit Boulevard, Suite 201, Broomfield, CO 80021, USA \\ ${ }^{2}$ Forensic Research and Analysis, Oregon Health and Science University, 425 NW 10th Avenue, Suite 306, Portland, OR 97209, USA \\ Correspondence should be addressed to John Pitts; jpitts@centenoschultz.com
}

Received 19 May 2014; Revised 14 July 2014; Accepted 28 July 2014; Published 7 September 2014

Academic Editor: Jozef Zustin

Copyright (c) 2014 Christopher Centeno et al. This is an open access article distributed under the Creative Commons Attribution License, which permits unrestricted use, distribution, and reproduction in any medium, provided the original work is properly cited.

\begin{abstract}
Introduction. We investigated the use of autologous bone marrow concentrate (BMC) with and without an adipose graft, for treatment of knee osteoarthritis (OA). Methods. Treatment registry data for patients who underwent BMC procedures with and without an adipose graft were analyzed. Pre- and posttreatment outcomes of interest included the lower extremity functional scale (LEFS), the numerical pain scale (NPS), and a subjective percentage improvement rating. Multivariate analyses were performed to examine the effects of treatment type adjusting for potential confounding factors. The frequency and type of adverse events (AE) were also examined. Results. 840 procedures were performed, 616 without and 224 with adipose graft. The mean LEFS score increased by 7.9 and 9.8 in the two groups (out of 80), respectively, and the mean NPS score decreased from 4 to 2.6 and from 4.3 to 3 in the two groups, respectively. AE rates were $6 \%$ and $8.9 \%$ in the two groups, respectively. Although pre- and posttreatment improvements were statistically significant, the differences between the groups were not. Conclusion. BMC injections for knee OA showed encouraging outcomes and a low rate of AEs. Addition of an adipose graft to the BMC did not provide a detectible benefit over BMC alone.
\end{abstract}

\section{Introduction}

Knee osteoarthritis $(\mathrm{OA})$ is a significant health problem with increasing impact on public health [1]. In 2009 there were approximately 600,000 total knee arthroplasties (TKAs) performed for knee OA, more than double the number performed 10 years earlier [2]. Total or partial joint arthroplasty surgeries are highly invasive procedures, requiring surgical resection of all or parts of the joint and insertion of a prosthesis [3]. Complications can be significant and include death, pulmonary embolism, stroke, and myocardial infarction [4-7]. While many patients who undergo TKA experience improved function and decreased symptoms, many others continue to have some degree of ongoing pain. A recent investigation of post-TKA symptoms reported chronic pain in $88 \%$ of patients who have had the surgery [8].

Nonsurgical alternatives to joint arthroplasty such as hyaluronic acid (HA) injections for knee OA are appealing due to lower cost and decreased morbidity $[9,10]$.
The treatment is less effective in patients with more severe disease and often only provides temporary relief lasting a few months $[9,10]$. Autologous biologic therapies are also promising, with early data showing that platelet rich plasma (PRP) injection for knee OA may be of benefit for patients with mild to moderate osteoarthritis [11]. Two recent trials of HA versus PRP injections for knee OA demonstrated the superiority of PRP $[12,13]$. However, PRP is less effective for patients with more severe OA [11].

Injection of autologous stem cells into the knee is a potentially promising treatment for moderate to severe OA. Mesenchymal stem cells are readily available in an outpatient setting and can be accessed via needle aspiration from a patient's bone marrow, as well as other sources [14]. Mesenchymal stem cells are multipotent and thus have the capability of differentiating into cartilage and bone [14, 15]. Early clinical studies using both isolated mesenchymal stem cells and bone marrow aspirate concentrate to treat osteoarthritis have been encouraging [16-19]. Another tissue that is a 
rich source of stem cells is adipose tissue [20, 21]. Several small studies have reported encouraging clinical results using adipose processed stromal vascular fraction (SVF) [22, 23]. Stem cell treatments could potentially provide a safe, less invasive, and nonsurgical treatment for knee OA; however, limited evidence for efficacy of this type of treatment exists in the literature. The purpose of this study is to expand the literature on safety and efficacy of BMC treatment of knee OA and explore whether adding adipose affects the results.

In the present study we evaluated the safety, efficacy, and differences of two stem cell therapies for knee OA using data gathered from a treatment registry. The first therapy was a same-day procedure using autologous bone marrow aspirate concentrate (BMC) alone, and the second was also a sameday procedure using BMC, but with the addition of adiposederived lipoaspirate.

\section{Methods}

2.1. Setting and Participants. This is a longitudinal analysis of prospectively gathered registry data. We used a private knee registry, which is an ongoing prospective survey system that was designed to follow up specific protocols of autologous mesenchymal stem cells, bone marrow concentrate, and platelets rich plasma based treatment. Registry data for all patients who underwent a BMC procedure for knee OA from April 2010 to December 2013 were included in the study. Only patients who had responded to the outcome and complications questionnaires at 1 month and 3, 6, and 12 months following the procedure were included. There were 17 outpatient facilities that contributed patients to the registry, although the majority of cases (67.9\%) were performed at a single center at which the primary author (CJC) is affiliated. Two patient groups were followed: the first received BMC and platelet rich plasma using a specified treatment protocol described in (group A) and the second received the same therapy plus the addition of an adipose fat graft (the lipoaspirate) (group B). The treatment protocols are described in detail in the "Procedure Descriptions" section. The indications for the second cohort were similar to those for the first, and the addition of the fat graft was at the discretion of the clinician. The data was collected prospectively and analyzed retrospectively.

2.2. Data Sources. Patients were enrolled in a treatment registry and tracked prospectively via an electronic database system using ClinCapture software (Clinovo Clinical Data Solutions, Sunnyvale, California; http://www.clinovo .com/clincapture). The program includes an automated emailing system to send patients clinical outcome questionnaires at a predetermined posttreatment frequency. In the present study we tracked patient response to treatment by (1) a subjective improvement rating scale from $-100 \%$ worse to $100 \%$ improved; (2) the lower extremity functional (LEFS) questionnaire; and (3) the numeric pain scale (NPS) for symptom severity. Complications were monitored by e-mail or during clinic visit preoperatively and at 1 month, 3 months, and 6 months and annually after the procedure by a dedicated registry staff. Nonresponders were contacted by phone and/or e-mail. We have previously published a number of studies using data from the same registry $[17,24-28]$.

2.3. Outcomes of Interest. The outcomes of interest were patients' report of any serious or other adverse events, percentage of reported positive or negative change on a -100 to $100 \%$ subjective improvement rating scale, changes in activities of daily living as measured by the lower extremity functional scale (see Table 1), and pain measured by the numeric pain scale (NPS) at set time points following the procedure. Patients were asked to rate their average pain during that week at the area being treated. The response was restricted to $0-10$ scale with no decimals allowed. Marking 0 indicated no pain and marking 10 indicated the worst possible pain. For the improvement rating scale, patients were asked the following question: "Compared to your condition prior to the procedure, what percent difference have you seen in your condition?" The response would range from $-100 \%$ worse to $100 \%$ better with $0 \%$ indicating no change. No decimals were allowed in this scale as well. Efficacy was measured by the intragroup changes in LEFS and NPS.

2.4. Adjudication of Adverse Events. Patients were sent questionnaires to elicit adverse events at 1 month, 3 months, and 6 months and annually. These questionnaires included the following questions: "Did you experience any complications you believe may be due to the procedure (i.e. infection, illness, etc.)? If "Yes", please explain" and "Have you been diagnosed with any new illness since the procedure? If "Yes", please explain." Any untoward or unfavorable medical occurrence that was reported was sent to the physician for adjudication. The treating physician or one of the authors (CJC) then determined through patient interview or chart review, based on the US Department of Health and Human Services guidelines [29], whether the condition was preexisting, unexpected, mild/moderate/severe, related to the therapeutic agent or procedure, or resolved/ongoing/fatal.

2.5. Covariates. In our analysis we included and accounted for a number of potentially confounding variables including age, gender, BMI, and severity of disease. Age was categorized into 3 groups: 50 years or younger (referent group), 51-60 years, and older than 60 years. BMI was categorized into below 25 (referent group), 25-29.9, and 30 or higher. The baseline severity of $\mathrm{OA}$ as well as candidacy for the procedure was graded following the Kellgren-Lawrence (KL) scale [30], in which KL1 was assigned a "Good" candidacy grade, KL2 was assigned a "Fair" grade, and KL3 and KL4 were assigned a "Poor" grade. These categories match the imaging-determined disease severity [31].

2.6. Statistical Analyses. Baseline characteristics were described using the mean and standard deviation for continuous variables and frequency and proportion for categorical variables. Baseline differences between the two groups were assessed using Student's $t$-test for continuous 
TABLE 1: Lower extremity function scale (LEFS).

Instructions

We are interested in knowing whether you are having any difficulty at all with the activities listed below because of your lower limb problem for which you are currently seeking attention. Please provide an answer for each activity.

Today, do you or would you have any difficulty at all with the following:

\begin{tabular}{|c|c|c|c|c|c|c|}
\hline & Activities & $\begin{array}{l}\text { Extremely difficult or } \\
\text { unable to perform } \\
\text { activity }\end{array}$ & $\begin{array}{l}\text { Quite a bit of } \\
\text { difficulty }\end{array}$ & $\begin{array}{l}\text { Moderate } \\
\text { difficulty }\end{array}$ & $\begin{array}{l}\text { A little bit of } \\
\text { difficulty }\end{array}$ & $\begin{array}{c}\text { No } \\
\text { difficulty }\end{array}$ \\
\hline (1) & $\begin{array}{l}\text { Any of your usual work, housework, or } \\
\text { school activities }\end{array}$ & $\square 0$ & $\square 1$ & $\square 2$ & $\square 3$ & $\square 4$ \\
\hline$(2)$ & $\begin{array}{l}\text { Your usual hobbies, recreational or sporting } \\
\text { activities }\end{array}$ & $\square 0$ & $\square 1$ & $\square 2$ & $\square 3$ & $\square 4$ \\
\hline (3) & Getting into or out of the bath & $\square 0$ & $\square 1$ & $\square 2$ & $\square 3$ & $\square 4$ \\
\hline$(4)$ & Walking between rooms & $\square 0$ & $\square 1$ & $\square 2$ & $\square 3$ & $\square 4$ \\
\hline$(5)$ & Putting on your shoes or socks & $\square 0$ & $\square 1$ & $\square 2$ & $\square 3$ & $\square 4$ \\
\hline (6) & Squatting & $\square 0$ & $\square 1$ & $\square 2$ & $\square 3$ & $\square 4$ \\
\hline (7) & $\begin{array}{l}\text { Lifting an object, like a bag of groceries, } \\
\text { from the floor }\end{array}$ & $\square 0$ & $\square 1$ & $\square 2$ & $\square 3$ & $\square 4$ \\
\hline$(8)$ & $\begin{array}{l}\text { Performing light activities around your } \\
\text { home }\end{array}$ & $\square 0$ & $\square 1$ & $\square 2$ & $\square 3$ & $\square 4$ \\
\hline$(9)$ & $\begin{array}{l}\text { Performing heavy activities around your } \\
\text { home }\end{array}$ & $\square 0$ & $\square 1$ & $\square 2$ & $\square 3$ & $\square 4$ \\
\hline$(10)$ & Getting into or out of a car & $\square 0$ & $\square 1$ & $\square 2$ & $\square 3$ & $\square 4$ \\
\hline (11) & Walking 2 blocks & $\square 0$ & $\square 1$ & $\square 2$ & $\square 3$ & $\square 4$ \\
\hline$(12)$ & Walking a mile & $\square 0$ & $\square 1$ & $\square 2$ & $\square 3$ & $\square 4$ \\
\hline (13) & $\begin{array}{l}\text { Going up or down } 10 \text { stairs (about } 1 \text { flight of } \\
\text { stairs) }\end{array}$ & $\square 0$ & $\square 1$ & $\square 2$ & $\square 3$ & $\square 4$ \\
\hline (14) & Standing for 1 hour & $\square 0$ & $\square 1$ & $\square 2$ & $\square 3$ & $\square 4$ \\
\hline$(15)$ & Sitting for 1 hour & $\square 0$ & $\square 1$ & $\square 2$ & $\square 3$ & $\square 4$ \\
\hline$(16)$ & Running on even ground & $\square 0$ & $\square 1$ & $\square 2$ & $\square 3$ & $\square 4$ \\
\hline (17) & Running on uneven ground & $\square 0$ & $\square 1$ & $\square 2$ & $\square 3$ & $\square 4$ \\
\hline (18) & Making sharp turns while running fast & $\square 0$ & $\square 1$ & $\square 2$ & $\square 3$ & $\square 4$ \\
\hline (19) & Hopping & $\square 0$ & $\square 1$ & $\square 2$ & $\square 3$ & $\square 4$ \\
\hline$(20)$ & Rolling over in bed & $\square 0$ & $\square 1$ & $\square 2$ & $\square 3$ & $\square 4$ \\
\hline
\end{tabular}

variables and chi square test or Fisher's exact test for categorical variables. For adverse events, we reported the frequency of events in each group per category. Intragroup changes in NPS and LEFS (differences in the pre- and posttreatment scores) were evaluated using the Wilcoxon signed-rank test, a nonparametric test for dependent samples. We examined the outcomes differences between the study groups using the Wilcoxon rank-sum test, a nonparametric test for independent samples. Multivariate analyses were performed to examine the effects of treatment type adjusting for potential confounding factors (covariates) utilizing the logistic regression analysis of binary outcomes. Logistic regression modelling is a well-known statistical method commonly used in medical research for predicting dichotomous outcomes (such as improvement versus nonimprovement) and finding associations between independent and dependent variables [32, 33]. In this study, logistic regression was modeled for functional and symptomatic improvement, which was defined as a $\geq 9$ point increase in the LEFS score, $\geq 2$ points drop in the NPS score, and $\geq 50 \%$ improvement as measured on the improvement rating scale. The cut points for LEFS and NPS changes were selected based on the minimally important clinical differences (MICD) reported in the medical literature, while the $50 \%$ improvement cut point was selected arbitrarily $[34,35]$. As no decimals were allowed in the NPS scale, the MICD was considered to be 2 instead of 1.2. The effects of treatment type and covariates were described by reporting the odds ratios and their $95 \%$ confidence intervals. Separate models were constructed for each dependent variable (LEFS, NPS, and improvement rating scale). The baseline scales were stratified into upper and lower groups to control for confounding due to baseline score differences. We were also interested to see whether different functional and symptomatic presenting groups demonstrate different effects and associations. Each group was then analyzed 
independently. We used the complete case analysis approach where subjects with missing observations were deleted. All analyses were performed utilizing the SAS 9.4 software [36].

\subsection{Procedure Descriptions}

2.7.1. Preinjection for All Patients. The first step of the treatment was a preinjection of a hypertonic dextrose solution into the knee joint or other painful extra-articular knee structures two to five days prior to injection of the bone marrow concentrate. The purpose of this preinjection was to introduce a chemical irritant to the joint in order to prompt a brief inflammatory response. Intra-articular needle placement was confirmed on ultrasound or fluoroscopy. If fluoroscopy was used, Iodixanol (Visipaque, NDC\# 04072223-06) radiographic contrast was injected to confirm intraarticular flow in the joint. This was followed by injection of 3-5 ccs of $12.5 \%$ dextrose (NDC\# 0409-6648-02) and $0.1 \%$ lidocaine (NDC\# 0409-4276-02) in normal saline (NDC\# 0409-4888-50).

2.7.2. Harvest and Preparation of the Bone Marrow Concentrate (Groups $A$ and B). All patients underwent a bone marrow aspiration. Prior to the procedure the patients were restricted from taking corticosteroids and nonsteroidal anti-inflammatory drugs (NSAIDs) for at least 2 weeks as these medications can reduce healing [37-41]. Whole bone marrow aspirate was harvested from the patients' posterior superior iliac crest under ultrasound or fluoroscopic guidance. Approximately $10-15 \mathrm{cc}$ of bone marrow aspirate was withdrawn from 6-8 sites (approximately 3-4 on each side) into heparinized syringes. There were 1,000 units of heparin (NDC\# 25021-403-01 and 25021-404-01) per 1 cc of whole bone marrow aspirate drawn into syringe. The aspirate was processed by hand in a sterile ISO-7 class clean room and in ISO-5 class laminar flow cabinets to isolate the buffy coat through centrifugation. This isolation produced $1-3 \mathrm{cc}$ of BMC injectate which was then transported via sterile means back to the operating room. Coincident with this harvest procedure approximately $60 \mathrm{ccs}$ of heparinized IV venous blood was drawn to be used for isolating platelet rich plasma (PRP) and platelet lysate (PL). To prepare the PRP, plasma was prepped via centrifugation at $200 \mathrm{~g}$ to separate plasma and buffy coat layers from the red blood cells. The resultant liquid lying above the concentrated solids (supernatant) was red cell/white cell poor. To prepare the PL, PRP was drawn off and stored at $-20^{\circ}$ Celsius; platelet bodies were recentrifuged, and the supernatant was drawn off.

2.7.3. Reinjection of the Bone Marrow Concentrate (Groups A and $B$ ). Needle placement into the joint was accomplished utilizing fluoroscopy or ultrasound as described above with intra-articular placement confirmed. The injectate consisted of bone marrow concentrate, PRP, and PL. This was injected intra-articularly and into painful or otherwise damaged structures. For example, if a meniscus tear was detected on MRI, the patient's meniscus was also injected under ultrasound guidance into areas of decreased echogenicity.
Based on medical need, infrequent additional platelet rich plasma injections may have been provided by the treating physician.

After the procedure the patients were given activity instructions and bracing if they had one compartment dominant disease. A posttreatment off-loader brace was commonly prescribed for the most involved compartment with the patient being given instructions to wear the brace with all weight bearing activity for 6 weeks. For patella-femoral compartment dominant OA patients, a patellar stabilizer brace was used. Patients were discharged with instructions to be light weight bearing for several days if there was significant post-op pain but then to return to full weight bearing as soon as feasible. Post-op activity sheets were provided to the patient, which described a gradual return to full activities over 6 weeks. The patients were encouraged to participate in physical therapy, but this was not required nor controlled.

\subsubsection{Lipoaspirate Harvest and Reinjection (Group B Only).} For this subgroup, at the time of the bone marrow draw, a miniliposuction was performed under ultrasound guidance and minimally processed adipose tissue was injected into the articular space. For the harvest of adipose tissue, patients were placed prone or in the lateral decubitus position and an area in the posterior superior buttocks or lateral thigh was anesthetized. The area was imaged under ultrasound and a Tulip Twin Port Harvester (\#harvtwn) was moved back and forth in the subcutaneous tissue to break up the adipose tissue. Approximately 5-15 cc of lipoaspirate was then drawn into a $60 \mathrm{cc}$ syringe containing heparin (NDC\# 25021-403-01 and 25021-402-01) and using a Tulip Snaplok (\#Snap_60) to maintain suction. The lipoaspirate was minimally processed via low speed centrifugation or by allowing the layers to settle over several hours and the top oil layer was drawn off. The tissue was then injected into the articular space with the BMC using an 18 gauge needle between the meniscus on the most painful side and the over lying collateral ligament, at a volume of 5-10 cc.

\section{Results}

There were 616 procedures performed on 518 patients in group A and 224 procedures performed on 163 patients in group B, for a total of 840 treated knees in 681 patients. There were 98 and 61 patients who underwent bilateral procedures in groups $\mathrm{A}$ and $\mathrm{B}$, respectively. Mean age, BMI, and percent male were 54.3 years, 26.5 , and $64.5 \%$ in group A and 59.9, 27.0, and 53.1\% in group B, respectively (Table 2). There were 196 (31.8\%) bilateral procedures in group A and $122(54.5 \%)$ bilateral procedures in group B. An additional $77(12.5 \%)$ patients in group A and 25 (11.2\%) patients in group B underwent additional PRP injections after their initial procedure. Radiographic data sufficient for OA severity classification were available for 646 out of 840 knees in both groups $(76.9 \%)$. The majority of patients were Caucasian (White), constituting $89.3 \%$ of group A and $88.8 \%$ of group B. 
TABLE 2: Baseline characteristics of the study groups (group A: bone marrow concentrate (BMC), group B: BMC and adipose graft, BMI: body mass index, LEFS: lower extremity functional scale, NPS: numeric pain scale, SD: standard deviation, KL: Kellgren-Lawrence scale, and * indicates a statistically significant difference between groups).

\begin{tabular}{|c|c|c|c|c|c|}
\hline & \multicolumn{2}{|c|}{ Group A } & \multicolumn{2}{|c|}{ Group B } & \multirow{2}{*}{$P$ value } \\
\hline & $N$ & Mean (SD) & $N$ & Mean (SD) & \\
\hline Age & 615 & $54.3(14.1)$ & 223 & $59.9(10.3)$ & $<0.001^{*}$ \\
\hline BMI & 561 & $26.5(4.4)$ & 202 & $27(4.2)$ & $0.039^{*}$ \\
\hline Baseline LEFS & 335 & $45.3(15.9)$ & 119 & $42.8(14.5)$ & 0.134 \\
\hline \multirow[t]{3}{*}{ Baseline NPS } & 370 & $4.2(2.4)$ & 141 & $4.4(2.4)$ & 0.350 \\
\hline & \multicolumn{2}{|c|}{ Group A } & \multicolumn{2}{|c|}{ Group B } & $P$ value \\
\hline & $N$ & $\%$ & $N$ & $\%$ & $P$ value \\
\hline Gender & 616 & & 224 & & $0.003^{*}$ \\
\hline Male & 397 & $(64.5)$ & 119 & $(53.1)$ & \\
\hline Female & 219 & $(35.5)$ & 105 & $(46.9)$ & \\
\hline Grade & 470 & & 166 & & 0.294 \\
\hline KL1 & 223 & $(48.5)$ & 69 & $(41.6)$ & \\
\hline KL2 & 145 & $(30.2)$ & 58 & $(34.9)$ & \\
\hline KL3-4 & 102 & $(21.3)$ & 39 & $(23.5)$ & \\
\hline Procedures per patient & 616 & & 224 & & $<0.001^{*}$ \\
\hline 1 (unilateral) & 420 & $(68.2)$ & 102 & $(45.5)$ & \\
\hline 2 (bilateral) & 196 & $(31.8)$ & 122 & $(54.5)$ & \\
\hline
\end{tabular}

TABLE 3: Baseline, follow-up, and changes in the symptomatic and functional scales for patients with available baseline and follow-up data (group A: bone marrow concentrate (BMC), group B: BMC and adipose graft, LEFS: lower extremity functional scale, NPS: numeric pain scale, SD: standard deviation, and $*$ indicates a statistically significant difference between groups).

\begin{tabular}{|c|c|c|c|c|c|}
\hline & \multicolumn{2}{|c|}{ Group A } & \multicolumn{2}{|c|}{ Group B } & \multirow{2}{*}{$P$ value } \\
\hline & $N$ & Mean (SD) & $N$ & Mean (SD) & \\
\hline \multicolumn{6}{|l|}{ Clinical scales } \\
\hline Improvement rating scale & 408 & $46.8(38)$ & 166 & $39.3(39.8)$ & $0.030^{*}$ \\
\hline LEFS (baseline) & 205 & $46.1(15.8)$ & 91 & $43.6(14.9)$ & - \\
\hline LEFS (follow-up) & 205 & $54(17.9)$ & 91 & $53.4(14.7)$ & - \\
\hline NPS (baseline) & 220 & $4(2.3)$ & 103 & $4.3(2.0)$ & - \\
\hline NPS (follow-up) & 220 & $2.6(2.3)$ & 103 & $3(2.3)$ & - \\
\hline \multicolumn{6}{|l|}{ Changes from the baseline } \\
\hline Change in LEFS & 205 & $7.9(16.1)$ & 91 & $9.8(14.2)$ & 0.335 \\
\hline Change in NPS & 220 & $-1.4(2.6)$ & 103 & $-1.3(2.5)$ & 0.761 \\
\hline \multicolumn{6}{|l|}{ Follow-up (in months) } \\
\hline Improvement rating scale & 408 & $10.4(9.4)$ & 166 & $10.7(8.1)$ & - \\
\hline LEFS & 205 & $6.2(5.0)$ & 91 & $5.7(3.8)$ & - \\
\hline NPS & 220 & $7(6.6)$ & 103 & $6.7(5.3)$ & - \\
\hline
\end{tabular}

Survey response rates for improvement rating scale were $66.2 \%$ (408 of 616 procedures) for group A and 74.1\% (166 of 224 procedures) for group B. The averaged postprocedure time of last available reported improvement was 10.4 months for group A and 10.7 months for group B (Table 3). Mean reported improvement was $46.8 \%$ for group A and $39.3 \%$ for group B at final follow-up. The response rate for the last available LEFS was $33.3 \%$ at an average of 6.2 months for group A after procedure and $40.6 \%$ at 5.7 months for group $B$. The mean LEFS changes from baseline were 7.93 points for group A and 9.8 points for group $\mathrm{B}(P \leq 0.001$ for intragroup differences). The response rate for the NPS questionnaire was $35.7 \%$ at an average of 7.0 months for group A and $46.0 \%$ at 6.7 months for group B. Patients in group A reported a mean baseline pain level of $4.0 / 10$ versus $2.6 / 10$ at final followup. The 1.4 decrease in NPS scores is a $35.3 \%$ drop relative to baseline. Patients in group $B$ reported a mean baseline of $4.3 / 10$ versus $3.0 / 10$ at final follow-up $(P \leq 0.001$ for intragroup differences). The 1.31-point decrease is a $30.2 \%$ drop relative to baseline. The only intergroup difference in treatment response that reached statistical significance was the subjective percentage improvement scale. 
Two additional subgroup analyses were performed in order to examine the differences among the patients undergoing bilateral procedures versus unilateral procedures, as well as those who received additional PRP treatment versus those who did not. Neither of the subgroups demonstrated significantly different results.

3.1. Survey Response Safety. Out of 840 procedures followed for an average of 17.7 months (range 1-41 months) there were 57 reported adverse events (AEs), including 37 in group A and 20 in group B (6\% and $8.9 \%$ of total patients, resp.). AEs were categorized, frequency and outcomes recorded, and they were adjudicated to a relationship to the procedure (see Table 4 for details). No clear trends could be ascertained with regard to types of complaints and the different procedures. Three AEs (rate of $0.4 \%$ of all patients) were graded as severe; however, none were adjudicated to be secondary to the procedure, nor were they associated with reports of ongoing disability.

3.2. Logistic Regression Modeling. There were no statistically significant differences in outcomes between group A (reference group) and group B (Table 5). For both groups combined, outcome was significantly impacted by baseline LEFS score $\leq 45$, gender, and BMI. Females were more likely to report improvement on the dichotomized LEFS scale compared to males $[\mathrm{OR}=3.44(1.5-8.2)]$ and dichotomized NPS outcomes $[\mathrm{OR}=2.6(1.0-6.6)]$. The 2 higher BMI groups were more likely to report improvement on the LEFS scale as well, with an OR of 3.5 (1.2-9.8) for the 25-29.9 BMI group relative to the lowest BMI group and an OR of 3.0 (1.0-8.6) for the $\geq 30$ BMI group relative to the lowest BMI group. Female patients were more likely to report a drop in the NPS score of 2 or more, an effect only detected among patients with baseline score of 5 or higher.

KL2 patients were significantly more likely (2.2 times) to report $\geq 50 \%$ improvement on the reported outcome scale in comparison with the reference group (KL3-4 grade).

\section{Discussion}

Self-rated functional and pain scores all showed statistically significant positive changes from baseline in both treatment groups. Although the LEFS score mean changes in both groups were greater than the potential error for the questionnaire of 5.3 points, only the mean change in group $\mathrm{B}$ was greater than the minimal clinically important difference (MCID) of 9 [34]. The mean change in group A did not exceed the MCID. The mean pain decrease of both knee OA groups exceeded the MCID for visual analog pain scales when applied to a Numerical Pain Scale (1-10 metric) of 1.2 points [35]. We were surprised to see that there was no obvious benefit from the addition of the lipoaspirate. For example, while group B met the MCID for the LEFS questionnaire, it showed a lesser drop in pain as measured by NPS. Both groups reported positive percent improvement, but group A patients reported a greater improvement rating than group $\mathrm{B}$.

There was no correlation observed between age and outcome in the models, a finding that is in keeping with
TABLE 4: Group A: bone marrow concentrate (BMC), Group B: BMC and adipose graft. Number of adverse events reported in each group classified by category, severity, relation to preexisting condition, procedure and injected component, and outcomes.

\begin{tabular}{|c|c|c|}
\hline & Group A & Group B \\
\hline \multicolumn{3}{|l|}{ Category } \\
\hline Pain/swelling & 23 & 13 \\
\hline Miscellaneous & 7 & 2 \\
\hline Skin reactions & 1 & 0 \\
\hline Neurologic & 0 & 2 \\
\hline Neoplasm & 2 & 0 \\
\hline Immune/allergic & 2 & 0 \\
\hline Cardiac & 0 & 2 \\
\hline Bleeding/hematoma & 2 & 0 \\
\hline Renal & 0 & 1 \\
\hline \multicolumn{3}{|l|}{ Severity } \\
\hline Mild & 26 & 14 \\
\hline Moderate & 9 & 5 \\
\hline Severe & 2 & 1 \\
\hline Related to preexisting condition & 9 & 5 \\
\hline \multicolumn{3}{|l|}{ Relation to procedure } \\
\hline Definitely related & 4 & 5 \\
\hline Likely related & 0 & 0 \\
\hline Possibly related & 17 & 12 \\
\hline Unlikely related & 11 & 2 \\
\hline Not related & 5 & 1 \\
\hline \multicolumn{3}{|l|}{ Relation to injected components } \\
\hline Definitely related & 1 & 3 \\
\hline Likely related & 0 & 0 \\
\hline Possible related & 16 & 8 \\
\hline Unlikely related & 14 & 4 \\
\hline Not related & 6 & 5 \\
\hline \multicolumn{3}{|l|}{ Outcome } \\
\hline Resolved/recovered & 22 & 17 \\
\hline Ongoing & 8 & 3 \\
\hline Not recovered & 1 & 0 \\
\hline Fatal & 2 & 0 \\
\hline Unknown & 3 & 0 \\
\hline Not categorized & 2 & 0 \\
\hline Total & $37(6 \%)$ & $20(8.9 \%)$ \\
\hline
\end{tabular}

the variability seen in prior reports that have examined age related effects. As an example, in one study younger patients demonstrated better outcomes with knee microfracture procedure to treat osteochondral defects [42], and in another study autologous chondrocyte implantation was noted to demonstrate similar age related effects [43]. Other authors have found no such relationship for cartilage repair procedures [44]. There was also a correlation between lower severity of arthritis and better improvement on the subjective percentage improvement rating scale, but this correlation did not extend to the NPS or LEFS outcomes. Thus, we cannot easily interpret if severity of arthritis based on the KL grading scale is predictive of outcomes in this study. 
TABLE 5: Adjusted odds ratios and $95 \%$ confidence intervals for lower extremity functional scale improvement ( $\triangle$ LEFS $\geq 9$ points), decreased NPS score (VAS drop $\geq 2$ points), and reporting $\geq 50 \%$ improvement on the improvement rating scale (group A: bone marrow concentrate (BMC), group B: BMC and adipose graft, BMI: body mass index, LEFS: lower extremity functional scale, NPS: numeric pain scale, KL: Kellgren-Lawrence scale, $*$ indicates a statistically significant odds ratio, and Ref: referent group).

\begin{tabular}{|c|c|c|c|c|c|}
\hline & \multicolumn{2}{|c|}{ LEFS outcomes } & \multicolumn{2}{|c|}{ NPS outcomes } & \multirow{2}{*}{$\begin{array}{l}\text { Improvement rating } \\
\text { scale outcomes } \\
(N=422)\end{array}$} \\
\hline & $\begin{array}{c}\text { Baseline } \\
\text { LEFS } \leq 45 \\
(N=111)\end{array}$ & $\begin{array}{c}\text { Baseline LEFS } \\
=46-70 \\
(N=102)\end{array}$ & $\begin{array}{l}\text { Baseline NPS } \\
\geq 5(N=101)\end{array}$ & $\begin{array}{c}\text { Baseline NPS } \\
=2-4(N=77)\end{array}$ & \\
\hline Group B & $0.8(0.3-2.1)$ & $1.3(0.5-3.6)$ & $1.3(0.5-3.2)$ & $1.6(0.6-4.6)$ & $0.7(0.4-1.1)$ \\
\hline Group A & 1 (Ref) & 1 (Ref) & 1 (Ref) & 1 (Ref) & 1 (Ref) \\
\hline Age $>60$ & $0.4(0.2-1.3)$ & $1.1(0.4-2.9)$ & $0.4(0.1-1.3)$ & $2.2(0.6-8.5)$ & $1.4(0.9-2.3)$ \\
\hline Age $51-60$ & $0.4(0.1-1.2)$ & $0.6(0.2-2)$ & $0.3(0.1-1.2)$ & $2.5(0.6-10.5)$ & $1.5(0.9-2.4)$ \\
\hline Age $\leq 50$ & 1 (Ref) & 1 (Ref) & 1 (Ref) & 1 (Ref) & 1 (Ref) \\
\hline $\mathrm{BMI} \geq 30$ & $3(1.0-8.6)^{*}$ & $0.7(0.1-4.1)$ & $0.9(0.3-3)$ & $0.3(0.1-1.2)$ & $1(0.6-1.8)$ \\
\hline BMI 25-29.9 & $3.5(1.2-9.8)^{*}$ & $1.7(0.7-4.2)$ & $1(0.3-3.2)$ & $0.4(0.1-1.4)$ & $1.2(0.8-1.9)$ \\
\hline $\mathrm{BMI}<25$ & 1 (Ref) & 1 (Ref) & 1 (Ref) & 1 (Ref) & 1 (Ref) \\
\hline Female & $3.4(1.5-8.2)^{*}$ & $1.3(0.6-3.2)$ & $2.6(1.0-6.6)^{*}$ & $1.1(0.4-2.9)$ & $1.4(0.9-2.1)$ \\
\hline Male & 1 (Ref) & 1 (Ref) & 1 (Ref) & 1 (Ref) & 1 (Ref) \\
\hline KL1 & $0.9(0.3-3)$ & $1.6(0.4-6.1)$ & $1(0.3-3.2)$ & $0.9(0.2-4.6)$ & $1.7(0.9-2.9)$ \\
\hline KL2 & $0.9(0.3-2.7)$ & $2.2(0.6-8.6)$ & $1(0.3-3.2)$ & $0.8(0.1-4.2)$ & $2.2(1.2-3.9)^{*}$ \\
\hline KL3-4 & 1 (Ref) & 1 (Ref) & 1 (Ref) & 1 (Ref) & 1 (Ref) \\
\hline
\end{tabular}

In this present study, lower functioning female patients and those with higher pain levels were more likely to report an improvement in comparison with male patients. These findings are in keeping with results previously reported in treatment registry studies for total knee arthroplasty $[45,46]$ and also consistent with the previous reports indicating that women are less likely to need knee arthroplasty revision [47]. These findings are reported with caution, as significant differences were seen only in the LEFS and NPS metrics and not in the self-reported improvement scale. Thus, the real impact of the observed differences is difficult to characterize.

An unexpected finding was that higher BMI patients in the lower functioning subset were more likely to report functional improvement than lower BMI patients. The result is inconsistent with what prior authors have reported. For example, in a 2013 review, the authors reported poorer objective and functional scores in morbidly obese versus normal to obese patients following knee arthroplasty [48]. Obese patients are also known to experience more perioperative complications and increased failure rates with knee arthroplasty [49-51]. The relationship has not been reported consistently, however, as there are also reports in the literature for microfracture and total knee arthroplasty procedures that indicate that obesity is not a factor in outcomes [51, 52]. There is not a readily apparent explanation for our observation that obesity was a positive factor for functional outcomes.

Pain/swelling was the most commonly reported adverse event. This was generally self-limited and resolved without any intervention. There was no significant difference between group A and group B. There was a trend for more reported pain/swelling in group $B$, which could have been associated with the proinflammatory effects of adipose oil being placed into the joint [53] or it may have been artifactual. Seven patients reported ongoing pain/soreness complaints, which were deemed to be related to either the OA disease process or the treatment failure. There were no significant differences between the groups for such complaints.

The miscellaneous category of AEs included complaints such as clicking, popping, catching, or instability in the joint, a self-limited feeling of asymmetry, muscle cramping, and no improvement. There was minimal difference between the groups in this category. The skin category included self-limited itching/rash (1). Both patients who reported bleeding/hematoma had self-limited hematomas at the bone marrow aspirate site. One patient visited the emergency room and was imaged there, but treatment was with supportive care only. One patient in the immune/allergic category reported an acute unrelated viral infection with lethargy and another reported a self-limited allergic reaction to the skin anesthetic. There were two patients who reported neoplasm, but neither were in the lower extremity (breast and gastric).

The overall safety of the procedure was substantially better than for total knee arthroplasty. The serious adverse event rate in one registry study tracking $>15,000$ arthroplasty patients was reported at $5.6 \%$, with a $0.2 \%$ mortality rate [54]. Even if all SAEs reported in our study were due to the procedures, the rate of $0.4 \%$ would be far less than the SAE rates reported for joint arthroplasty. In addition, even if the one mortality due to gastric cancer was adjudicated as being caused by the procedure, the mortality rate of $0.1 \%$ would be less than that commonly seen in arthroplasty procedures.

The results from the procedures described are limited by the fact that the data collection was via a prospective treatment registry. Thus, the analyses described here are 
based on self-reported data, which limits the internal validity of the study because of the increased chance of reporting bias [55]. The most significant limitation of the study is, of course, the lack of randomization of patients into a placebo or alternate treatment control group. Additionally, there was no randomization of the lipoaspirate treatment group versus the nonlipoaspirate group.

\section{Conclusions}

This report of registry data on two groups of patients receiving $\mathrm{BMC}$ injections for knee $\mathrm{OA}$ shows encouraging results. We found that the addition of a lipoaspirate to the bone marrow concentrate did not provide any measured benefit over BMC alone. The reported complications for the two therapy groups were very low and far less than those commonly reported for knee arthroplasty procedures. While our results are encouraging, more study is needed using randomized controlled trails to confirm the reported effects.

\section{Conflict of Interests}

Dr. Christopher Centeno is a shareholder and director of Regenerative Sciences, LLC.

\section{Authors' Contribution}

Drs. Christopher Centeno, John Pitts, Michael Freeman, and Hasan Al-Sayegh all participated in study design, data analysis and interpretation, and preparation of the paper.

\section{References}

[1] R. C. Lawrence, D. T. Felson, C. G. Helmick et al., "Estimates of the prevalence of arthritis and other rheumatic conditions in the United States. Part II," Arthritis and Rheumatism, vol. 58, no. 1, pp. 26-35, 2008.

[2] A. M. Weinstein, B. N. Rome, W. M. Reichmann et al., "Estimating the burden of total knee replacement in the United States.", The Journal of Bone and Joint Surgery, vol. 95, no. 5, pp. 385-392, 2013.

[3] J. N. Insall, "Historical Development, classification, and characteristics of knee prostheses," in Surgery of the Knee, J. N. Insall, Ed., Churchill Livingstone, New York, NY, USA, 2nd edition, 1993.

[4] S. M. Javad Mortazavi, H. Kakli, O. Bican, M. Moussouttas, J. Parvizi, and R. H. Rothman, "Perioperative stroke after total joint arthroplasty: prevalence, predictors, and outcome," Journal of Bone and Joint Surgery A, vol. 92, no. 11, pp. 20952101, 2010.

[5] M. J. Morris, R. G. Molli, K. R. Berend, and A. V. Lombardi, "Mortality and perioperative complications after unicompartmental knee arthroplasty," Knee, vol. 20, no. 3, pp. 218-220, 2013.

[6] A. Lalmohamed, P. Vestergaard, C. Cooper et al., "Timing of stroke in patients undergoing total hip replacement and matched controls: a nationwide cohort study," Stroke, vol. 43, no. 12, pp. 3225-3229, 2012.

[7] A. Lalmohamed, P. Vestergaard, C. Klop et al., "Timing of acute myocardial infarction in patients undergoing total hip or knee replacement: a nationwide cohort study," Archives of Internal Medicine, vol. 172, no. 16, pp. 1229-1235, 2012.

[8] P. R. Pinto, T. McIntyre, R. Ferrero, V. Araújo-Soares, and A. Almeida, "Persistent pain after total knee or hip arthroplasty: differential study of prevalence, nature, and impact," Journal of Pain Research, vol. 6, pp. 691-703, 2013.

[9] M. Benke and B. Shaffer, "Viscosupplementation treatment of arthritis pain," Current Pain and Headache Reports, vol. 13, no. 6, pp. 440-446, 2009.

[10] A. J. Cianflocco, "Viscosupplementation in patients with osteoarthritis of the knee," Postgraduate Medicine, vol. 125, no. 1, pp. 97-105, 2013.

[11] A. Khoshbin, T. Leroux, D. Wasserstein et al., "The efficacy of platelet-rich plasma in the treatment of symptomatic knee osteoarthritis: a systematic review with quantitative synthesis," Arthroscopy, vol. 29, no. 12, pp. 2037-2048, 2013.

[12] F. Say, D. Gürler, K. Yener, M. Bülbül, and M. Malkoc, "Platelet-rich plasma injection is more effective than hyaluronic acid in the treatment of knee osteoarthritis," Acta Chirurgiae Orthopaedicae et Traumatologiae Cechoslovaca, vol. 80, no. 4, pp. 278-283, 2013.

[13] E. Kon, G. Filardo, A. Di Martino, and M. Marcacci, "Plateletrich plasma (PRP) to treat sports injuries: evidence to support its use," Knee Surgery, Sports Traumatology, Arthroscopy, vol. 19, no. 4, pp. 516-527, 2011.

[14] M. F. Pittenger, A. M. Mackay, S. C. Beck et al., "Multilineage potential of adult human mesenchymal stem cells," Science, vol. 284, no. 5411, pp. 143-147, 1999.

[15] C. Lange, J. Schroeder, M. V. Lioznov, and A. R. Zander, "High-potential human mesenchymal stem cells," Stem Cells and Development, vol. 14, no. 1, pp. 70-80, 2005.

[16] "Autologous mesenchymal stem cells for treating knee osteoarthritis," Managed Care, vol. 22, no. 8, pp. 15-16, 2013.

[17] C. J. Centeno, D. Busse, J. Kisiday, C. Keohan, M. Freeman, and D. Karli, "Increased knee cartilage volume in degenerative joint disease using percutaneously implanted, autologous mesenchymal stem cells," Pain Physician, vol. 11, no. 3, pp. 343-353, 2008.

[18] C. J. Centeno, "Clinical challenges and opportunities of mesenchymal stem cells in musculoskeletal medicine," $P M \diamond R$, vol. 6, no. 1, pp. 70-77, 2014.

[19] Y. Qi, G. Feng, and W. Yan, "Mesenchymal stem cell-based treatment for cartilage defects in osteoarthritis," Molecular Biology Reports, vol. 39, no. 5, pp. 5683-5689, 2012.

[20] J. I. Huang, P. A. Zuk, N. F. Jones et al., "Chondrogenic potential of multipotential cells from human adipose tissue," Plastic and Reconstructive Surgery, vol. 113, no. 2, pp. 585-594, 2004.

[21] J. Pak, "Autologous adipose tissue-derived stem cells induce persistent bone-like tissue in osteonecrotic femoral heads," Pain Physician, vol. 15, no. 1, pp. 75-85, 2012.

[22] L. Casteilla, V. Planat-Benard, P. Laharrague, and B. Cousin, "Adipose-derived stromal cells: their identity and uses in clinical trials, an update," World Journal of Stem Cells, vol. 3, no. 4, pp. 25-33, 2011.

[23] G. Desando, C. Cavallo, F. Sartoni et al., "Intra-articular delivery of adipose derived stromal cells attenuates osteoarthritis progression in an experimental rabbit model," Arthritis Research and Therapy, vol. 15, no. 1, article R22, 2013.

[24] C. J. Centeno, D. Busse, J. Kisiday, C. Keohan, M. Freeman, and D. Karli, "Regeneration of meniscus cartilage in a knee treated with percutaneously implanted autologous mesenchymal stem cells," Medical Hypotheses, vol. 71, no. 6, pp. 900-908, 2008. 
[25] C. J. Centeno, J. R. Schultz, M. Cheever et al., "Safety and complications reporting update on the re-implantation of cultureexpanded mesenchymal stem cells using autologous platelet lysate technique," Current Stem Cell Research and Therapy, vol. 6, no. 4, pp. 368-378, 2011.

[26] C. J. Centeno, J. R. Schultz, M. Cheever, B. Robinson, M. Freeman, and W. Marasco, "Safety and complications reporting on the re-implantation of culture-expanded mesenchymal stem cells using autologous platelet lysate technique," Current Stem Cell Research and Therapy, vol. 5, no. 1, pp. 81-93, 2010.

[27] C. J. Centeno, J. R. Schultz, M. Cheever, M. Freeman, B. Robinson, and S. Faulkner, "A Case Series of Percutaneeous Treatment of Non-Union Fractures with Autologous, Culture Expanded, Bone Marrow Dervied, Mesenchymal Stem Cells and Platelet Lysate," Bioengineering \& Biomedical Science, 2011.

[28] C. J. Centeno and M. D. Freeman, "Percutaneous injection of autologous, culture-expanded mesenchymal stem cells into carpometacarpal hand joints: a case series with an untreated comparison group," Wiener Medizinische Wochenschrift, vol. 164, no. 5-6, pp. 83-87, 2013.

[29] U.S. Department of Health and Human Services, Ed., Guidance for Clinical Investigators, Sponsors, and IRBs Adverse Event Reporting to IRBs-Improving Human Subject Protection, Office of the Commissioner, the Center for Drug Evaluation and Research (CDER), the Center for Biologics Evaluation and Research (CBER), the Center for Devices and Radiological health $(\mathrm{CDRH})$, and the Good CLinical Practice Program (GCPP) at the Food and Drug Administration, 2009.

[30] J. H. Kellgren and J. S. Lawrence, "Radiological assessment of osteo-arthrosis," Annals of the Rheumatic Diseases, vol. 16, no. 4, pp. 494-502, 1957.

[31] M. Sowers, C. A. Karvonen-Gutierrez, J. A. Jacobson, Y. Jiang, and M. Yosef, "Associations of anatomical measures from MRI with radiographically defined knee osteoarthritis score, pain, and physical functioning," Journal of Bone and Joint Surgery A, vol. 93, no. 3, pp. 241-251, 2011.

[32] S. C. Bagley, H. White, and B. A. Golomb, "Logistic regression in the medical literature: standards for use and reporting, with particular attention to one medical domain," Journal of Clinical Epidemiology, vol. 54, no. 10, pp. 979-985, 2001.

[33] F. I. Lewis and M. P. Ward, "Improving epidemiologic data analyses through multivariate regression modelling," Emerging Themes in Epidemiology, vol. 10, no. 1, article 4, 2013.

[34] J. M. Binkley, P. W. Stratford, S. A. Lott, and D. L. Riddle, “The Lower Extremity Functional Scale (LEFS): scale development, measurement properties, and clinical application," Physical Therapy, vol. 79, no. 4, pp. 371-383, 1999.

[35] A. M. Kelly, “The minimum clinically significant difference in visual analogue scale pain score does not differ with severity of pain," Emergency Medicine Journal, vol. 18, no. 3, pp. 205-207, 2001.

[36] SAS 9.4 Software, SAS Institute Inc, Cary, NC, USA, 2014.

[37] M. R. Chen and J. L. Dragoo, "The effect of nonsteroidal antiinflammatory drugs on tissue healing," Knee Surgery, Sports Traumatology, Arthroscopy, vol. 21, no. 3, pp. 540-549, 2013.

[38] M. E. Wiggins, P. D. Fadale, H. Barrach, M. G. Ehrlich, and W. R. Walsh, "Healing characteristics of a type I collagenous structure treated with corticosteroids," The American Journal of Sports Medicine, vol. 22, no. 2, pp. 279-288, 1994.

[39] W. Tsai, C. Hsu, C. P. C. Chen, M. J. L. Chen, M. Lin, and J. S. Pang, "Ibuprofen inhibition of tendon cell migration and down-regulation of paxillin expression," Journal of Orthopaedic Research, vol. 24, no. 3, pp. 551-558, 2006.

[40] W.-C. Tsai, F.-T. Tang, M.-K. Wong, and J.-H. S. Pang, "Inhibition of tendon cell migration by dexamethasone is correlated with reduced alpha-smooth muscle actin gene expression: a potential mechanism of delayed tendon healing," Journal of Orthopaedic Research, vol. 21, no. 2, pp. 265-271, 2003.

[41] P. Randelli, F. Randelli, P. Cabitza, and L. Vaienti, "The effects of COX-2 anti-inflammatory drugs on soft tissue healing: a review of the literature," Journal of Biological Regulators and Homeostatic Agents, vol. 24, no. 2, pp. 107-114, 2010.

[42] D. Goyal, S. Keyhani, E. H. Lee, and J. H. Hui, "Evidence-based status of microfracture technique: a systematic review of level I and II studies," Arthroscopy, vol. 29, no. 9, pp. 1579-1588, 2013.

[43] B. Moradi, E. Schönit, C. Nierhoff et al., "First-generation autologous chondrocyte implantation in patients with cartilage defects of the knee: 7 to 14 years' clinical and magnetic resonance imaging follow-up evaluation," Arthroscopy, vol. 28, no. 12, pp. 1851-1861, 2012.

[44] O. A. Behery, J. D. Harris, J. M. Karnes, R. A. Siston, and D. C. Flanigan, "Factors influencing the outcome of autologous chondrocyte implantation: a systematic review," Journal of Knee Surgery, vol. 26, no. 3, pp. 203-211, 2013.

[45] T. R. Liebs, W. Herzberg, A. M. Roth-Kroeger, W. Rüther, and J. Hassenpflug, "Women recover faster than men after standard knee arthroplasty," Clinical Orthopaedics and Related Research, vol. 469, no. 10, pp. 2855-2865, 2011.

[46] S. J. MacDonald, K. D. Charron, R. B. Bourne, D. D. Naudie, R. W. McCalden, and C. H. Rorabeck, "The John Insall award: gender-specific total knee replacement: prospectively collected clinical outcomes," Clinical Orthopaedics and Related Research, vol. 466, no. 11, pp. 2612-2616, 2008.

[47] P. L. Santaguida, G. A. Hawker, P. L. Hudak et al., "Patient characteristics affecting the prognosis of total hip and knee joint arthroplasty: a systematic review," Canadian Journal of Surgery, vol. 51, no. 6, pp. 428-436, 2008.

[48] M. J. McElroy, R. Pivec, K. Issa, S. F. Harwin, and M. A. Mont, "The effects of obesity and morbid obesity on outcomes in TKA," The Journal of Knee Surgery, vol. 26, no. 2, pp. 83-88, 2013.

[49] A. J. Samson, G. E. Mercer, and D. G. Campbell, "Total knee replacement in the morbidly obese: a literature review," ANZ Journal of Surgery, vol. 80, no. 9, pp. 595-599, 2010.

[50] M. S. Sridhar, C. D. Jarrett, J. W. Xerogeanes, and S. A. Labib, "Obesity and symptomatic osteoarthritis of the knee," Journal of Bone and Joint Surgery B, vol. 94, no. 4, pp. 433-440, 2012.

[51] G. N. Gillespie and A. J. Porteous, "Obesity and knee arthroplasty," Knee, vol. 14, no. 2, pp. 81-86, 2007.

[52] A. K. Amin, J. T. Patton, R. E. Cook, and I. J. Brenkel, "Does obesity influence the clinical outcome at five years following total knee replacement for osteoarthritis?" Journal of Bone and Joint Surgery B, vol. 88, no. 3, pp. 335-340, 2006.

[53] G. A. Tynan, C. H. Hearnden, E. Oleszycka et al., "Endogenous oils derived from human adipocytes are potent adjuvants that promote IL-1 $\alpha$-dependent inflammation," Diabetes, vol. 63, no. 6, pp. 2037-2050, 2014.

[54] P. J. Belmont Jr., G. P. Goodman, B. R. Waterman, J. O. Bader, and A. J. Schoenfeld, "Thirty-day postoperative complications and mortality following total knee arthroplasty: incidence and risk factors among a national sample of 15,321 patients," Journal of Bone and Joint Surgery A, vol. 96, no. 1, pp. 20-26, 2014.

[55] R. A. Ward and M. E. Brier, "Retrospective analyses of large medical databases: what do they tell us?" Journal of the American Society of Nephrology, vol. 10, no. 2, pp. 429-432, 1999. 


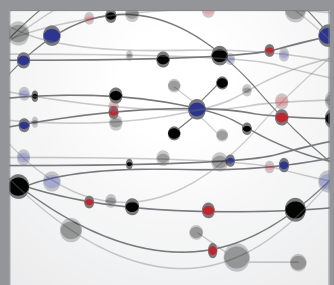

The Scientific World Journal
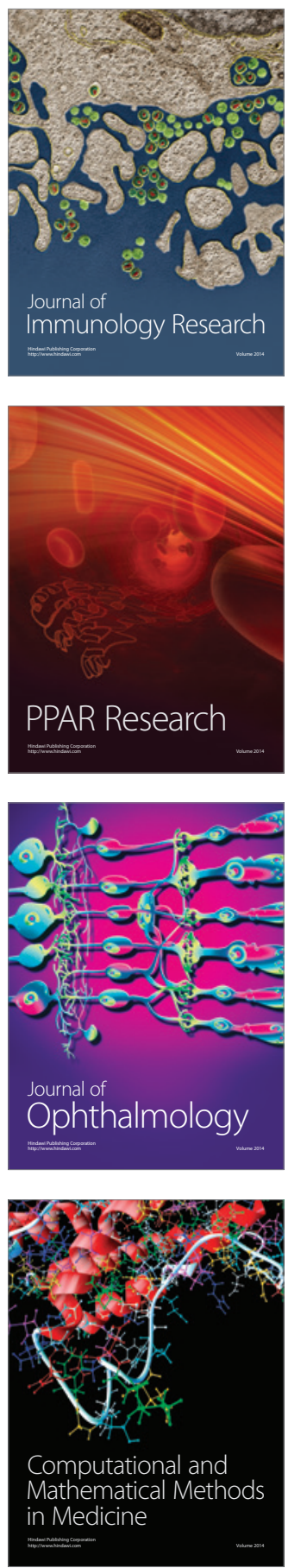

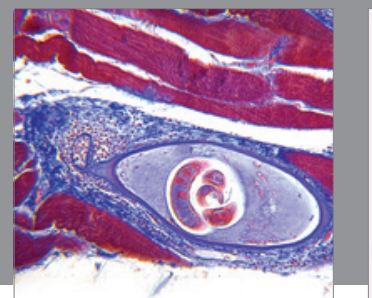

Gastroenterology

Research and Practice
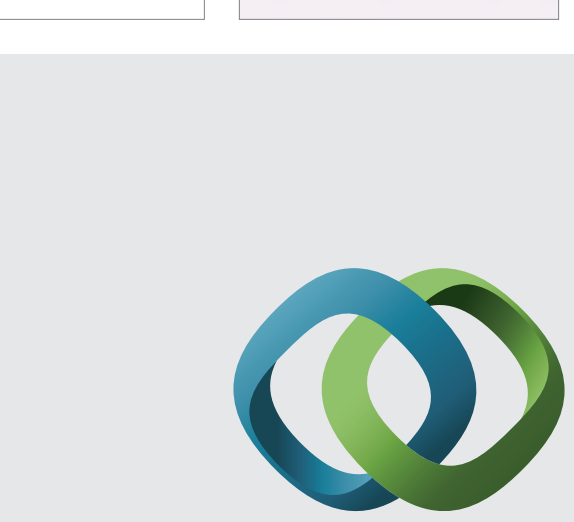

\section{Hindawi}

Submit your manuscripts at

http://www.hindawi.com
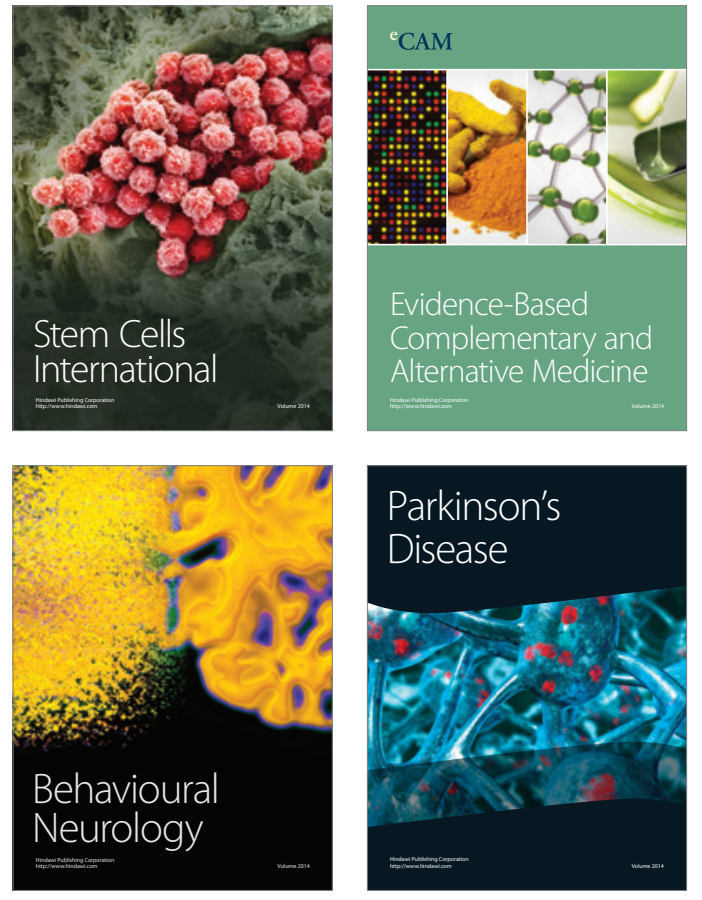
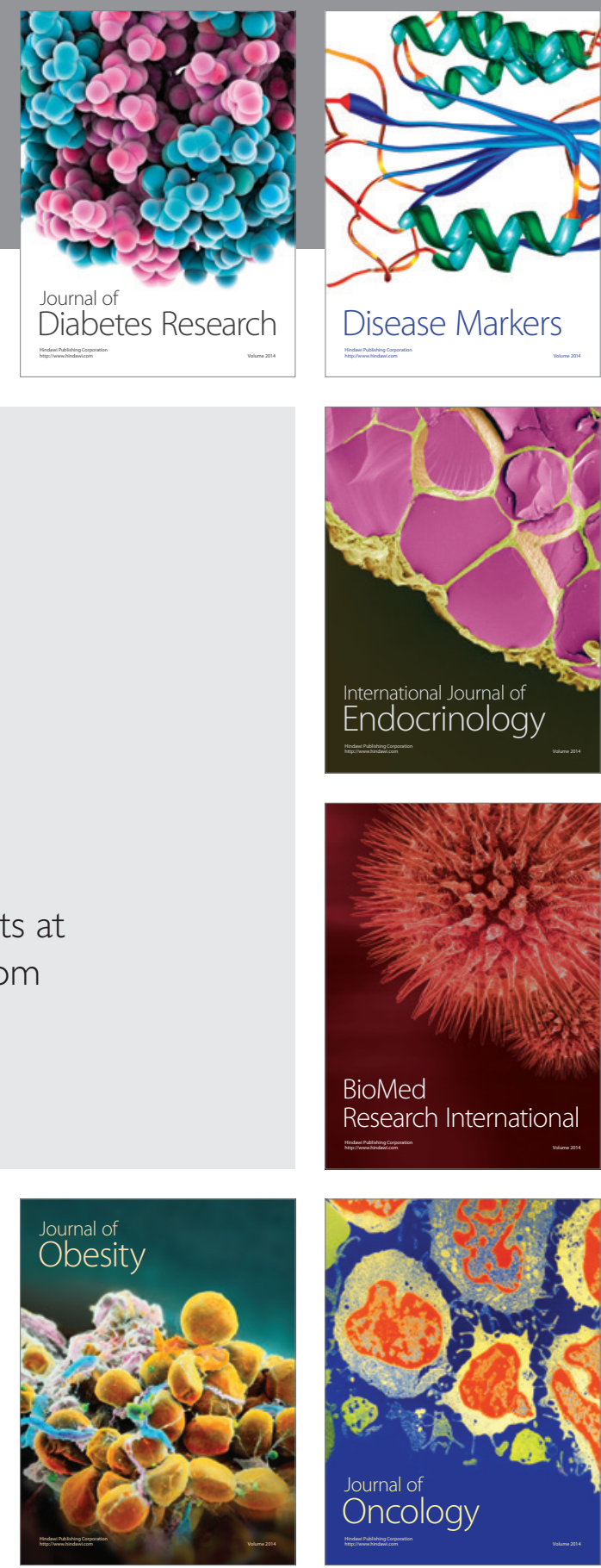

Disease Markers
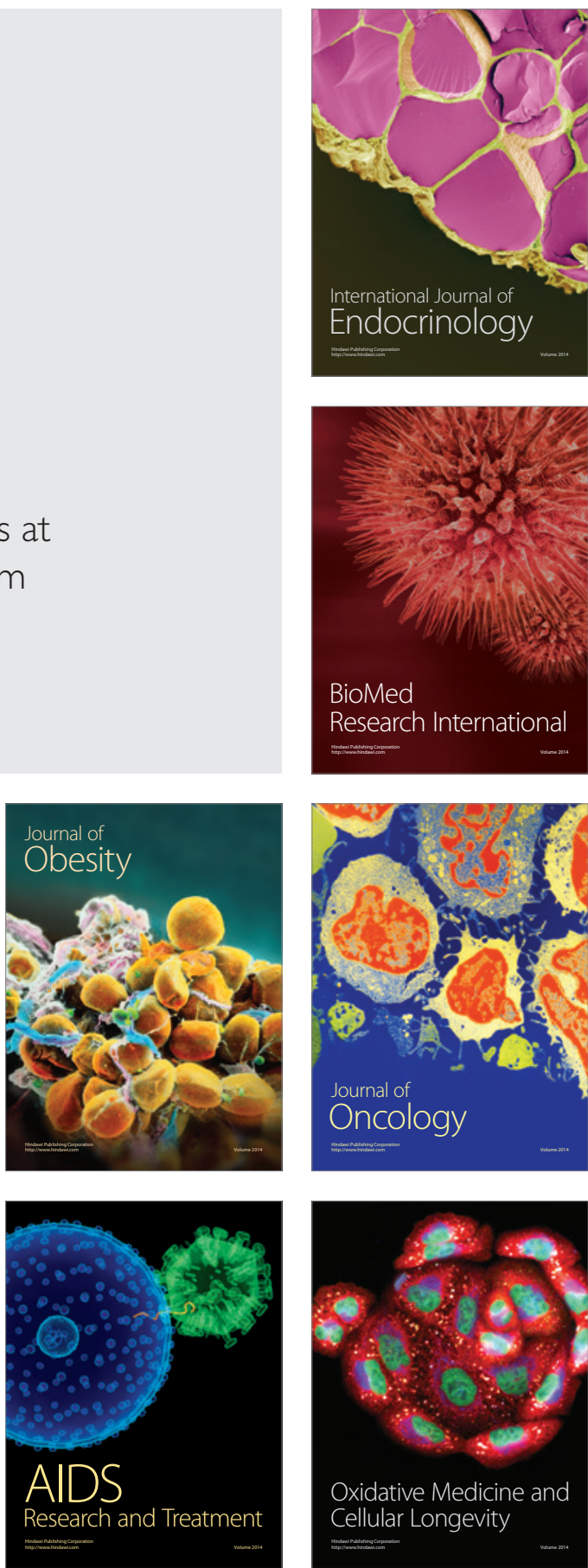